\title{
Classification of Homogeneous Regions of Strong Wind and Gust Wind in Korea
}

\author{
Hyunuk Kim, Baek-Jo Kim, Hyoung-Gu Nam, Jonghyeok Jeong, \\ Jae-Kwan Shim, Kyu Rang Kim, and Seungbum Kim \\ High Impact Weather Research Department, National Institute of Meteorological Sciences, \\ Korea Meteorological Administration, Korea
}

\begin{abstract}
In this study, based on the daily maximum wind speed and maximum instantaneous wind speed data recorded at 61 observation points operated by the Korea Meteorological Administration from 1993 to 2018, the self-organizing map clustering method was used to classify regions with similar characteristics of strong wind and gust wind occurrence and intensity. Characteristics of these regions were analyzed by averaging 30 variables related to wind for each cluster. As a result, 13 homogeneous regions of strong wind and gust wind in Korea were identified, which were clearly divided into regions of high and low strong wind frequency of occurrences. In most regions, the average daily maximum wind speed and maximum instantaneous wind speed were high in spring and winter. However, the average daily maximum wind speed and maximum instantaneous wind speed exceeding the criteria of strong wind $\left(14 \mathrm{~m} \mathrm{~s}^{-1}\right)$ and gust wind $\left(20 \mathrm{~m} \mathrm{~s}^{-1}\right)$ in this study were high in summer and autumn. Among the four clusters with high occurrence of strong wind and gust wind, one was classified as a specific region with high occurrence in summer and autumn. This results are likely to be beneficial to support regional customized special weather reports and disaster prevention.

(Citation: Kim, H., B.-J. Kim, H.-G. Nam, J. Jeong, J.-K. Shim, K. R. Kim, and S. Kim, 2020: Classification of homogeneous regions of strong wind and gust wind in Korea. SOLA, 16, 140-144, doi:10.2151/sola.2020-024.)
\end{abstract}

\section{Introduction}

Majority of previous studies related to wind in Korea have been regional classification studies focused on determining a stable supply of wind as a resource rather than on mitigating wind damage (Choi et al. 2009; Kim and Byun 2008; Lee et al. 2006; Park et al. 1994). Although the damage caused by strong winds has less impact than other disasters, it continues to occur and threatens human life (MOIS 2018). Strong winds damage not only facilities such as buildings, greenhouses, and barns, but also aquaculture and fishing gear (Lee et al. 2009; MOIS 1983-2018). In addition, more traffic and railroad accidents occur in the event of strong winds, and the risk of forest fires is increased (Kang et al. 2016; Lee 2007, 2010; Park et al. 2010). To mitigate such disasters, it is necessary to classify strong wind regions and establish appropriate disaster prevention measures for each region. In particular, research on regional classification is necessary because Korea contains clearly distinguished regions with high and low strong wind frequency (Kim et al. 2020). Most studies on climatological or meteorological regional classification focus mainly on rainfall and snowfall (Choi 1990; Kim et al. 2012; Kim et al. 2017; Moon and Kim 2001; Um et al. 2011). Research on classifying regions based on wind speed that can cause disasters is necessary. In this study, areas with similar characteristics of strong wind occurrence are classified and characteristics of grouped areas are analyzed. The results can be used to support regional customized weather forecasts, special weather reports, and disaster prevention measures.

Corresponding author: Hyunuk Kim, High Impact Weather Research Department, National Institute of Meteorological Sciences, N10-707, 7 Jukheon-gil, Gangneung-si, Gangwon-do 25457, Korea. E-mail: darzhyun @korea.kr

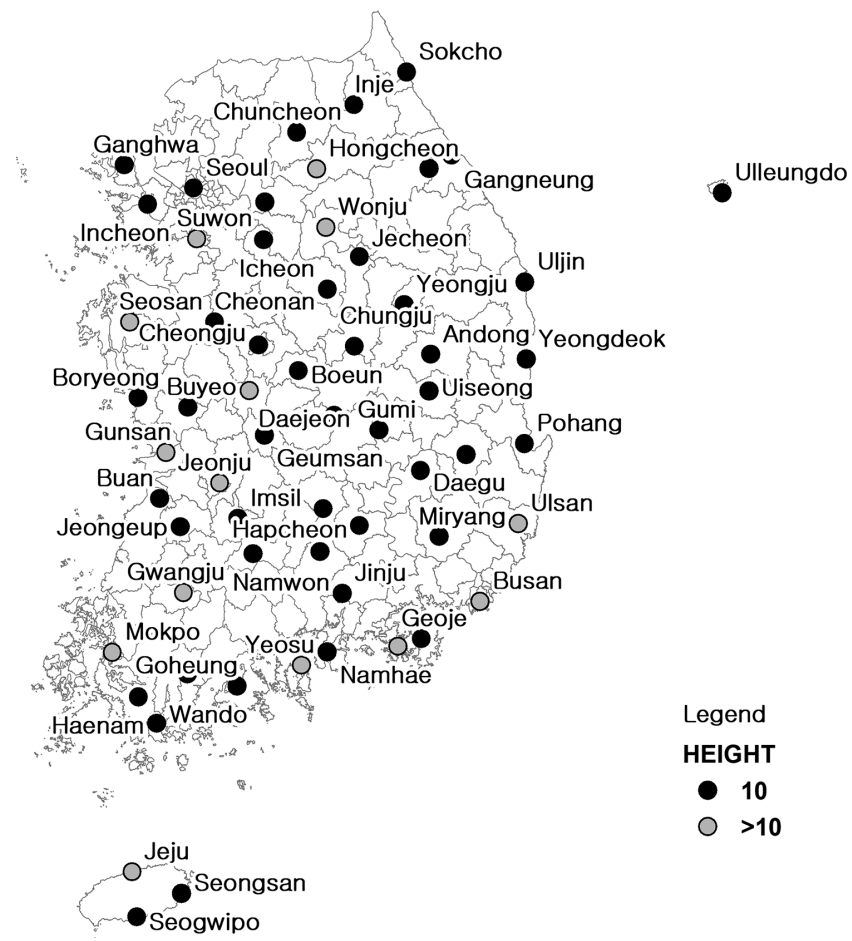

Fig. 1. Location of surface observation stations used in the study. Gray circles indicate stations with elevation of more than $10 \mathrm{~m}$.

Source: Climatological Spatio-Temporal Variation of Strong Wind in Korea (Kim et al. 2020)

\section{Data and study method}

\subsection{Data}

The study data include the daily maximum wind speed and the daily maximum instantaneous wind speed data recorded by the 61 Automated Synoptic Observing System (ASOS) stations operated by the Korea Meteorological Administration from 1993 to 2018 (Fig. 1). According to the ground weather observation guidelines, the wind speed measured $10 \mathrm{~m}$ from the ground is standard. As the height of the anemometer is different for each observation point, the following equation was used to correct the height (Jiang et al. 2010; Pryor et al. 2005; Wan et al. 2010).

$$
\frac{U\left(Z_{10}\right)}{U\left(Z_{a}\right)}=\left(\frac{Z_{10}}{Z_{a}}\right)^{\alpha}
$$

where $U$ is the wind speed, $Z_{10}$ represents $10 \mathrm{~m}$ height, $Z_{a}$ represents the actual observation height, and $\alpha$ is generally set to $1 / 7$ (Kim and Kim 2013; Peterson and Hennessey 1978; Weisser and Foxon 2003).

In this study, according to the criteria for a high wind advisory in Korea, strong wind (SW) has a daily maximum wind speed of $14 \mathrm{~m} \mathrm{~s}^{-1}$ or larger, and gust wind (GW) has a daily maximum instantaneous wind speed of $20 \mathrm{~m} \mathrm{~s}^{-1}$ or larger. For regional 
Table 1. Variables used in this study.

\begin{tabular}{|c|c|c|}
\hline Variable & Unit & Description \\
\hline T FRE SW & Number & Total number of strong wind \\
\hline T_FRE_GW & Number & Total number of gust wind \\
\hline AV̄R_W̄ S_SW & Number & Average of daily maximum wind speed \\
\hline AVR_WS_GW & Number & Average of daily maximum instantaneous wind speed \\
\hline AVR WS SW 14 & $\mathrm{~m} \mathrm{~s}^{-1}$ & Average of daily maximum wind speed over $14 \mathrm{~m} \mathrm{~s}^{-1}$ \\
\hline AVR WS GW 20 & $\mathrm{~m} \mathrm{~s}^{-1}$ & Average of daily maximum instantaneous wind speed over $20 \mathrm{~m} \mathrm{~s}^{-1}$ \\
\hline T_F_MA $\bar{M} \_S W$ & Number & Number of strong winds in spring \\
\hline T_F_JJA_SW & Number & Number of strong winds in summer \\
\hline T_F_SON_SW & Number & Number of strong winds in autumn \\
\hline T_F_DJF_SW & Number & Number of strong winds in winter \\
\hline T_A_MAM_M_SW & $\mathrm{m} \mathrm{s}^{-1}$ & Average of daily maximum wind speed in spring \\
\hline T_A_JJA_SW & $\mathrm{m} \mathrm{s}^{-1}$ & Average of daily maximum wind speed in summer \\
\hline T_A_SON_SW & $\mathrm{m} \mathrm{s}^{-1}$ & Average of daily maximum wind speed in autumn \\
\hline T_A_DJF_SW & $\mathrm{m} \mathrm{s}^{-1}$ & Average of daily maximum wind speed in winter \\
\hline T_A_MAM_SW_14 & $\mathrm{m} \mathrm{s}^{-1}$ & Average of daily maximum wind speed over $14 \mathrm{~m} \mathrm{~s}^{-1}$ in spring \\
\hline $\mathrm{T}^{-} \mathrm{A}^{-} \mathrm{JJA} \quad \mathrm{SW} \quad 1 \overline{4}$ & $\mathrm{~m} \mathrm{~s}^{-1}$ & Average of daily maximum wind speed over $14 \mathrm{~m} \mathrm{~s}^{-1}$ in summer \\
\hline $\mathrm{T}^{-} \mathrm{A}$ SON SW 14 & $\mathrm{~m} \mathrm{~s}^{-1}$ & Average of daily maximum wind speed over $14 \mathrm{~m} \mathrm{~s}^{-1}$ in autumn \\
\hline T_A_DJF_SW_14 & $\mathrm{m} \mathrm{s}^{-1}$ & Average of daily maximum wind speed over $14 \mathrm{~m} \mathrm{~s}^{-1}$ in winter \\
\hline T_F_MAT̄G & Number & Number of gust winds in spring \\
\hline $\mathrm{T}^{-} \mathrm{FJ} A \mathrm{GW}$ & Number & Number of gust winds in summer \\
\hline $\mathrm{TF} \mathrm{SON}$ GW & Number & Number of gust winds in autumn \\
\hline T_F_DJF_GW & Number & Number of gust winds in winter \\
\hline T_A_MAM_G_GW & $\mathrm{m} \mathrm{s}^{-1}$ & Average of daily maximum wind speed in spring \\
\hline $\mathrm{T}^{-} \mathrm{A} J \mathrm{JJ} \mathrm{GW}$ & $\mathrm{m} \mathrm{s}^{-1}$ & Average of daily maximum wind speed in summer \\
\hline $\mathrm{T}$ A SON GW & $\mathrm{m} \mathrm{s}^{-1}$ & Average of daily maximum wind speed in autumn \\
\hline T_A_DJF_GW & $\mathrm{m} \mathrm{s}^{-1}$ & Average of daily maximum wind speed in winter \\
\hline T_A_MAM̄G_GW_20 & & Average of daily maximum instantaneous wind speed over $20 \mathrm{~m} \mathrm{~s}^{-1}$ in spring \\
\hline T_A_JJA_GW_20 & $\mathrm{m} \mathrm{s}^{-1}$ & Average of daily maximum instantaneous wind speed over $20 \mathrm{~m} \mathrm{~s}^{-1}$ in summer \\
\hline $\mathrm{T}^{-} \mathrm{A}^{-} \mathrm{SON} \mathrm{G} \mathrm{G} \overline{\mathrm{W}} 20$ & $\mathrm{~m} \mathrm{~s}^{-1}$ & Average of daily maximum instantaneous wind speed over $20 \mathrm{~m} \mathrm{~s}^{-1}$ in autumn \\
\hline T_A_DJF_- GW_ē20 & $\mathrm{m} \mathrm{s}^{-1}$ & Average of daily maximum instantaneous wind speed over $20 \mathrm{~m} \mathrm{~s}^{-1}$ in winter \\
\hline
\end{tabular}

classification according to the characteristics of SW and GW, the variables listed in Table 1 were produced and used. The total number of variables is 30 . Among the variables, the frequency of occurrence was summed up, and the wind speed was averaged.

\subsection{Method}

This study used a self-organizing map (SOM), which has frequently been used for regional classification in previous studies (Kim et al. 2012; Kim et al. 2017; Lin and Chen 2006; Lu et al. 2006; Nishiyama et al. 2007). Matlab was used to perform the SOM. A review of SOM applications in meteorology and oceanography was provided in Liu and Weisberg (2011). SOM has many advantages over other conventional methods(Liu and Weisberg, 2005; Liu et al. 2006). A SOM is effective for mapping multi-dimensional data to a two-dimensional map (Budayan et al. 2009). Also, it has the strength to discover hidden and meaningful patterns of data (Arribas-Bel et al. 2011). Liu et al. (2016) proposed dual SOM applications, in which the SOM was applied to the spatial and temporal domains of the data, respectively. Our present work corresponds to the second part of the dual SOM analysis. The structure of SOM is divided into an input layer and a competition layer. In the competition layer, the number of nodes is randomly generated according to the input data, and all nodes are completely connected. Each node has a random initial weight value, and the value changes as the analysis proceeds. The weight value of the node becomes a representative value of the node after the analysis process is completed, and has the same dimensions as the input data. Input data is normalized to values between 0 and 1 . When the SOM analysis process starts, the similarity between all input values and weight values is calculated by Eq. (1). The node with the most similar weight value to the input is called the best matching unit (BMU).

$$
c(B M U)=\arg \min \left\|x(t)-m_{i}(t)\right\|
$$

where $x$ is an $n$-dimensional data vector of the input values, $m$ is an $n$-dimensional weight vector, and $t$ is time.

Then, the weight values of the BMU are updated by Eqs. (2) and (3), and the BMU is updated by Eq. (1).

$$
\begin{aligned}
& m_{i}(v)=m_{i}(t)+h_{c i}\left(t,\left\|r_{c}-r_{i}\right\|\left[x(t)-m_{i}(t)\right]\right. \\
& h_{c i}\left(t,\left\|r_{c}-r_{i}\right\|\right)=a(t) \cdot \exp \left(-\frac{\left\|r_{c}-r_{i}\right\|^{2}}{2 \sigma^{2}(t)}\right)
\end{aligned}
$$

where $h_{c i}$ is the neighborhood function, which is generally a Gaussian model; $a(t)$ is the learning rate, which decreases as training time progresses; $\sigma(t)$ is the width of the neighborhood function; and $\left\|r_{c}-r_{i}\right\|$ is the distance to the weight vector located in the neighborhood with the BMU.

This analysis process of the SOM is called training, and the training of the SOM ends when the weight value is no longer updated by successive iterations. The final selected weight value represents the input value. The weight values located nearby have a similar value compared to the weight values located at a distance. After the SOM training is completed, a cluster is formed based on the BMU. However, because SOM forms many clusters, the number of clusters is usually calculated using a secondary cluster. In this study, the K-means clustering method was used as the secondary clustering method. In addition, the Davies-Bouldin index (DBI) was used to objectively calculate the number of clusters (Vesanto and Alhomini 2000). The DBI is a measure that determines the number of clusters where the similarity between clusters is maximized and the similarity between data belonging to the same cluster is minimized. The lower the index, the more effective the clustering.

$$
v_{D B}(C)=\frac{1}{C} \sum_{K=1}^{C} \max \left\{\frac{S_{c}\left(Q_{k}\right)+S_{c}\left(Q_{l}\right)}{d_{c e}\left(Q_{k}, Q_{l}\right)}\right\}
$$

where $C$ is the number of clusters; $C_{k}$ is the center value of cluster $k ; S_{c}=\sum_{i}\left\|X_{i}-C_{k}\right\| / N_{k}$ is the distance between the center of the cluster and data contained in the cluster; $N_{k}$ is the number of data points in cluster $k$; and $d_{c e}=\left\|c_{k}-c_{i}\right\|$ is the distance between clusters $Q_{k}$ and $Q_{l}$.

Lastly, according to the analyzed results, the variables of each cluster were averaged to confirm the characteristics of SW and GW by cluster. 


\section{Results and discussion}

The first clustering process using SOM created 44 nodes based on the input data, and among them, the number of clusters selected as BMU was 25. The result of the secondary K-means clustering method was 13 clusters with a minimum DBI of 0.6145 (Fig. 2). For 2 to 15 clusters, DBI ranged from 0.6145 to 0.8268 . When the number of clusters was more than 16 , the DBI value increased rapidly.

Figure 3 shows the clusters that correspond to the 61 observation points used in the study. Although the clusters do not show a tendency to be spatially dense, similar characteristics may be exhibited at distant points due to effects of topography and geography on meteorological phenomena (Kim et al. 2012; $\mathrm{Lu}$ et al. 2006). In particular, wind speed is greatly influenced by terrain features (Kim and Kim 2013; Wu et al. 2018). Clusters 4, 6,10 , and 13 , shown with large triangles in Fig. 3, were identified as observation points where the occurrence frequency of SW and GW was relatively high. Areas with frequent SW and GW are mostly coastal, and some mountainous areas are included. The areas with low occurrence frequency of SW and GW were mostly found to be inland areas. These results are consistent with the results in Kim et al. (2020), which divided the top 25\% region and the bottom $75 \%$ region according to the frequency of SW and GW. This reaffirmed that the occurrence frequency of SW and GW differed greatly between regions in Korea.

Table 2 shows the results of averaged or summed variables related to SW and GW for each cluster. Shading (bold font) means that the characteristics of the variable are distinct. The most evident result is the occurrence frequency of SW and GW, confirming the large gap between clusters $4,6,10$, and 13 and other clusters. It is difficult to analyze the statistical characteristics of the clusters with low occurrence frequency of SW and GW because there are few occurrences. Therefore, in this study, characteristics were analyzed for clusters $4,6,10$, and 13 with high occurrence of SW and GW. Considering that the study period is 26 years, it is difficult to define clusters 10 and 13 as areas where SW and GW occur frequently. However, clusters 4 and 6, which include Ulleungdo, Yeosu, and Wando, can be defined as areas where SW and GW occur frequently. Among regions with relatively high occurrence of SW and GW, the occurrence of SW and GW in clusters 4, 6, and 13 were more than twice as frequent in spring and winter compared to summer and autumn. Also, the average daily maximum wind speed and maximum instantaneous wind speed in spring and winter were higher than in summer and autumn. These results are explained by the influence of the northwest seasonal winds in winter, the local strong winds in spring, and the frequent passage of the frontal depression (Kim et al. 2009; Kim et al. 2020). In contrast, the average daily maximum wind speed and maximum instantaneous wind speed exceeding the criteria of SW $\left(14 \mathrm{~m} \mathrm{~s}^{-1}\right)$ and GW $\left(20 \mathrm{~m} \mathrm{~s}^{-1}\right)$ defined in this study were high in summer and autumn. These results are thought to be greatly affected by typhoons, which occur mainly in summer and autumn. The average daily maximum wind speed and maximum instantaneous wind speed were generally high in spring and winter, and relatively low in summer and autumn, even in regions where SW and GW were less frequent.

Cluster 10, which includes Tongyeong, Seogwipo, and Seongsan, has a relatively high occurrence frequency of SW and GW. The overall wind characteristics of cluster 10 appeared similar to other regions. However, cluster 10 has been identified as a unique region where SW has a high occurrence in summer and autumn and GW has a high occurrence in spring and summer, unlike other regions. The observation points can be confirmed to be different from the surrounding points in Kim and Kim (2013)'s research on wind speed. The high occurrence of SW and GW in summer and autumn are generally judged to be the effects of typhoons. However, considering the range of the impact of typhoons, additional research is needed on the cause of this result because similar characteristics do not appear at nearby observation points.

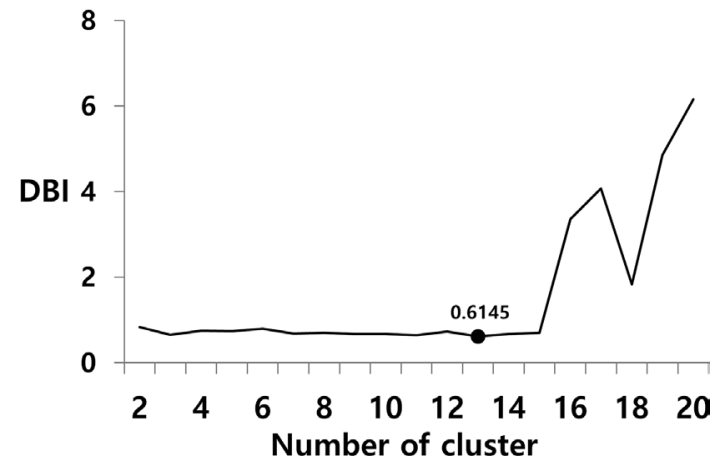

Fig. 2. Verification result of the Davies-Bouldin index (DBI) by number of clusters.

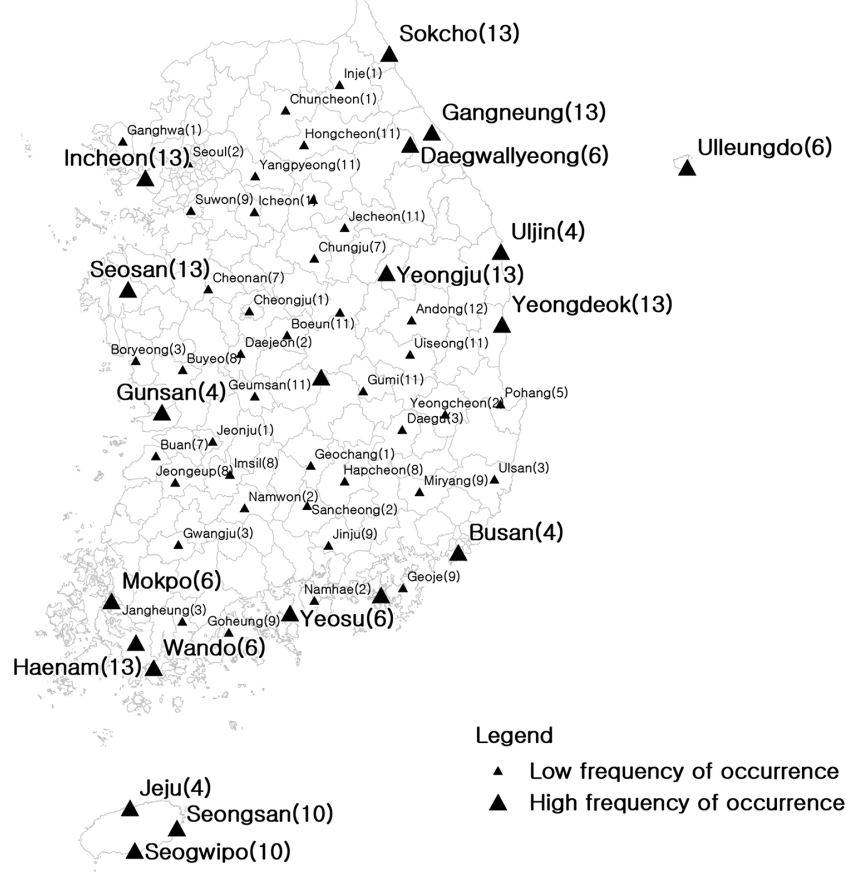

Fig. 3. Homogeneous regions of strong wind (SW) and gust wind (GW). Numbers in parentheses indicate cluster number. The sizes of the triangles correspond to the frequencies of occurrences of SW and GW.

\section{Summary and conclusions}

In this study, based on daily maximum wind speed and maximum instantaneous wind speed data, SOM was used to classify regions with similar characteristics of SW and GW occurrence and intensity. The characteristics of SW and GW for each cluster were analyzed by averaging each of the variables used in the study for each cluster. The results are as follows.

First, 13 optimal clusters were formed from 61 ASOS observation points based on 30 variables using wind data. Among these, it was possible to classify the clusters with high occurrence and the remaining clusters. The clusters with frequent occurrences of SW and GW were mainly coastal and mountainous areas, and the rest were inland areas. These results are consistent with the those of previous studies reported by Kim et al. (2020).

Second, among the clusters where the occurrence of SW and GW was relatively high, the frequency of occurrence in the cluster 4, which includes observation points in Uljin, Busan, Gunsan, and Jeju, and cluster 6, which includes observation points in Ulleungdo, Yeosu, and Wando was particulary high. 
Table 2. Characteristics of strong wind (SW) and gust wind (GW) by cluster. Shading (bold font) means that the characteristics of the variable are distinct.

\begin{tabular}{|c|c|c|c|c|c|c|c|c|c|c|c|c|c|c|}
\hline & \multirow{2}{*}{ Unit } & \multicolumn{13}{|c|}{ Cluster } \\
\hline & & 1 & 2 & 3 & 4 & 5 & 6 & 7 & 8 & 9 & 10 & 11 & 12 & 13 \\
\hline T_FRE_SW & Number & 1.1 & 5.5 & 12.6 & 139.3 & 5.0 & 393.4 & 3.0 & 1.8 & 3.8 & 46.0 & 0.5 & 1.5 & 44.1 \\
\hline T_FRE_GW & Number & 12.9 & 30.5 & 39.6 & 290.3 & 43.0 & 634.6 & 6.0 & 6.5 & 25.6 & 158.7 & 2.8 & 15.5 & 124.0 \\
\hline AVR_WS_SW & Number & 4.1 & 4.5 & 5.1 & 6.7 & 5.1 & 7.7 & 4.4 & 3.8 & 4.3 & 5.6 & 3.7 & 4.4 & 5.9 \\
\hline AVR_WS_GW & Number & 7.1 & 7.7 & 8.4 & 10.5 & 8.9 & 11.6 & 7.2 & 6.6 & 7.6 & 9.6 & 6.6 & 7.7 & 9.3 \\
\hline AVR_WS_SW_14 & $\mathrm{m} \mathrm{s}^{-1}$ & 11.1 & 15.8 & 15.8 & 16.3 & 16.3 & 15.9 & 14.9 & 18.5 & 16.5 & 16.7 & 7.6 & 14.6 & 15.6 \\
\hline AVR_WS_GW_20 & $\mathrm{m} \mathrm{s}^{-1}$ & 22.0 & 22.5 & 22.5 & 23.0 & 21.7 & 23.0 & 21.7 & 22.6 & 22.9 & 23.4 & 21.5 & 21.9 & 22.3 \\
\hline T_F_MAM_SW & Number & 0.0 & 2.2 & 2.8 & 41.0 & 0.0 & 121.0 & 1.0 & 0.0 & 0.0 & 9.7 & 0.0 & 1.5 & 15.1 \\
\hline T_F_JJA_SW & Number & 1.1 & 1.7 & 5.8 & 27.0 & 1.0 & 50.2 & 1.7 & 1.3 & 2.2 & 21.3 & 0.4 & 0.0 & 5.8 \\
\hline T_F_SON_SW & Number & 0.0 & 1.0 & 1.8 & 27.5 & 3.0 & 75.2 & 0.0 & 0.5 & 1.4 & 11.7 & 0.1 & 0.0 & 6.3 \\
\hline T_F_DJF_SW & Number & 0.0 & 0.7 & 2.2 & 43.8 & 1.0 & 147.0 & 0.3 & 0.0 & 0.2 & 3.3 & 0.0 & 0.0 & 17.0 \\
\hline T_A_MAM_SW & $\mathrm{m} \mathrm{s}^{-1}$ & 4.8 & 5.1 & 5.5 & 7.2 & 5.5 & 8.2 & 5.1 & 4.4 & 4.9 & 6.0 & 4.4 & 5.0 & 6.5 \\
\hline T_A_JJA_SW & $\mathrm{m} \mathrm{s}^{-1}$ & 4.0 & 4.2 & 5.0 & 6.2 & 4.8 & 6.6 & 4.2 & 3.7 & 4.2 & 5.4 & 3.4 & 3.7 & 5.0 \\
\hline T_A_SON_SW & $\mathrm{m} \mathrm{s}^{-1}$ & 3.7 & 4.0 & 4.6 & 6.2 & 4.9 & 7.2 & 4.0 & 3.4 & 3.8 & 5.4 & 3.3 & 3.9 & 5.4 \\
\hline T_A_DJF_SW & $\mathrm{m} \mathrm{s}^{-1}$ & 4.1 & 4.7 & 5.2 & 7.1 & 5.4 & 8.7 & 4.3 & 3.6 & 4.5 & 5.8 & 3.8 & 4.9 & 6.6 \\
\hline T_A_MAM̄SW_SW & $\mathrm{m} \mathrm{s}^{-1}$ & 0.0 & 14.8 & 14.9 & 15.6 & 0.0 & 15.7 & 14.2 & 0.0 & 0.0 & 15.2 & 0.0 & 14.6 & 15.2 \\
\hline T_A_JJA_SW_ $\overline{-} \overline{4}$ & $\mathrm{~m} \mathrm{~s}^{-1}$ & 11.1 & 9.3 & 16.2 & 16.7 & 14.6 & 16.8 & 15.4 & 17.9 & 16.0 & 16.9 & 5.8 & 0.0 & 10.0 \\
\hline T_A_SON_SW 14 & $\mathrm{~m} \mathrm{~s}^{-1}$ & 0.0 & 12.7 & 17.1 & 17.4 & 17.0 & 16.2 & 0.0 & 4.6 & 17.0 & 17.0 & 1.8 & 0.0 & 16.1 \\
\hline T_A_DJF_SW_14 & $\mathrm{m} \mathrm{s}^{-1}$ & 0.0 & 2.6 & 14.8 & 16.4 & 15.7 & 15.7 & 4.8 & 0.0 & 0.0 & 15.8 & 0.0 & 0.0 & 15.5 \\
\hline T_F_MAM_GW & Number & 4.9 & 9.3 & 8.6 & 84.3 & 12.0 & 200.2 & 0.7 & 0.8 & 5.2 & 45.3 & 0.6 & 4.5 & 42.3 \\
\hline T_F_JJA_GW & Number & 4.4 & 7.8 & 13.6 & 49.5 & 10.0 & 79.6 & 3.3 & 4.5 & 8.0 & 56.3 & 1.0 & 1.0 & 12.3 \\
\hline T_F_SON_GW & number & 1.3 & 5.7 & 8.6 & 58.3 & 9.0 & 119.4 & 0.7 & 1.3 & 6.4 & 33.3 & 1.1 & 4.5 & 24.0 \\
\hline T_F_DJF_GW & Number & 2.3 & 7.7 & 8.8 & 98.3 & 12.0 & 235.4 & 1.3 & 0.0 & 6.0 & 23.7 & 0.0 & 5.5 & 45.5 \\
\hline T_A_MAM_GW & $\mathrm{m} \mathrm{s}^{-1}$ & 8.3 & 8.7 & 9.1 & 11.2 & 9.7 & 12.3 & 8.3 & 7.6 & 8.5 & 10.0 & 7.8 & 8.8 & 10.3 \\
\hline T_A_JJA_GW & $\mathrm{m} \mathrm{s}^{-1}$ & 6.8 & 7.2 & 7.9 & 9.6 & 8.0 & 9.9 & 6.8 & 6.4 & 7.4 & 8.9 & 6.1 & 6.5 & 7.9 \\
\hline T_A_SON_GW & $\mathrm{m} \mathrm{s}^{-1}$ & 6.4 & 6.9 & 7.7 & 10.0 & 8.4 & 10.9 & 6.6 & 6.0 & 6.8 & 9.2 & 6.0 & 6.8 & 8.7 \\
\hline T_A_DJF_GW & $\mathrm{m} \mathrm{s}^{-1}$ & 7.0 & 8.1 & 8.7 & 11.4 & 9.6 & 13.2 & 7.0 & 6.5 & 7.7 & 10.2 & 6.7 & 8.6 & 10.6 \\
\hline T_A_MAM_GW_20 & $\mathrm{m} \mathrm{s}^{-1}$ & 22.2 & 21.6 & 21.7 & 22.4 & 21.5 & 22.7 & 7.0 & 10.1 & 20.9 & 22.7 & 10.8 & 22.1 & 22.0 \\
\hline T_A_JJA_GW_20 & $\mathrm{m} \mathrm{s}^{-1}$ & 18.9 & 22.9 & 23.4 & 23.8 & 21.2 & 24.2 & 21.5 & 22.8 & 23.7 & 24.3 & 10.8 & 20.4 & 22.3 \\
\hline T_A_SON_GW & $\mathrm{m} \mathrm{s}^{-1}$ & 18.4 & 23.8 & 22.9 & 23.9 & 22.8 & 23.2 & 7.2 & 17.5 & 24.1 & 24.2 & 18.6 & 21.7 & 22.6 \\
\hline T_A_DJF_GW_20 & $\mathrm{m} \mathrm{s}^{-1}$ & 21.9 & 21.8 & 21.1 & 22.8 & 21.6 & 22.6 & 22.1 & 0.0 & 17.3 & 22.4 & 0.0 & 21.7 & 22.1 \\
\hline
\end{tabular}

Third, in general, the average daily maximum wind speed and maximum instantaneous wind speed at all observation points were high in spring and winter. Furthermore, the occurrence of SW and $\mathrm{GW}$ was high in spring and winter. These results are explained by the influence of the northwest seasonal winds in winter, the local strong winds in spring, and the frequent passage of the frontal depression (Kim et al. 2009; Kim et al. 2020). However, daily maximum wind speed and maximum instantaneous wind speed exceeding the criteria of SW $\left(14 \mathrm{~m} \mathrm{~s}^{-1}\right)$ and $\mathrm{GW}\left(20 \mathrm{~m} \mathrm{~s}^{-1}\right)$ defined in this study were high in summer and autumn. This is judged to be the result of typhoons.

Fourth, cluster 10, which includes Tongyeong, Seogwipo, and Seongsan observation points, has similar wind characteristics to the other regions, but was identified as a unique region with high occurrence in summer and autumn, the cause of which requires further research.

Wind is an important phenomenon that reflects the Earth's atmospheric circulation and requires constant attention and research. This study analyzed regional characteristics by classifying the occurrence frequency and wind speed of SW and GW in Korea by season. It is possible to achieve effective damage reduction by managing each homogeneous area separately (Jun et al. 2008). The results of this study are likely to be beneficial to support regional customized weather forecasting, special weather reports, and disaster prevention measures.

\section{Acknowledgements}

This work was funded by the Korea Meteorological Administration Research and Development Program "Development and Application of Monitoring, Analysis and Prediction Technology for High Impact Weathers" under Grant (KMA2018-00223).

Edited by: S.-K. Park

\section{References}

Arribas-Bel, D., P. Nijkamp, and H. Scholten, 2011: Multidimensional urban sprawl in Europe: A self-organizing map approach. Comput. Environ. Urban Syst., 35, 263-275.

Choi, J. Y., H. K. Choi, G. M. Lee, K. H. Choi, M. H. Lim, S. G. Choi, J. Y. Lee, and S. G. Hwang, 2009: Considering the terrain and wind speed wind force generation. Proc. KIIEE Annual Conference, 301-304.

Choi, J. S., 1990: The classification of snowfall area and its regional characteristics of South Korea. J. Korean Geogr. Soc., 25, 35-48.

Jiang, Y., Y. Luo, Z. Zhao, and S. Tao, 2010: Changes in wind speed over China during 1956-2004. Theor. Appl. Climatol., 99, 421-430.

Jun, H. D., M. J. Park, G. Y. Kim, and J. W. Kim, 2008: Damage analysis of meteorological disasters for each district considering the characteristics of a district. J. Korean Soc. Hazard 
Mitig., 8, 75-82.

Kang, S. C., M. S. Won, and S. H. Yoon, 2016: Large fire forecasting depending on the changing wind speed and effective humidity in Korean red pine forests through a case study. $J$. Korean Assoc. Geogr. Information Studies, 19, 146-156.

Kim, B. J., S. L. Lee, H. K. Kim, and J. E. Yoo, 2006: On the characteristics of the damage and occurrence of high Winds in Korea. Korean Society of Steel Construction, 18, 79-86.

Kim, B. J., S.-L. Lee, and G.-U. Park, 2009: Characteristics of strong wind occurrence in the Southweatern region of Korea. J. Korean Soc. Hazard Mitig., 9, 37-44.

Kim, D. W., and H. R. Byun, 2008: Spatial and temporal distribution of wind resources over Korea. Atmosphere, 18, 172182.

Kim, H. U., B. J. Kim, H. G. Nam, J. H. Jung, and J. K. Shim, 2020: Climatological spatio-temporal variation of strong wind in Korea. Atmosphere, 30, 47-57.

Kim, H. U., J. K. Shim, and B. C. Choi, 2017: Homogeneous regions classification and regional differentiation of snowfall. J. Korean Assoc. Geogr. Information Studies, 20, 42-51.

Kim, H. U., C. Sohn, and S. O. Han, 2012: Identifying the optimal number of homogeneous regions for regional frequency analysis using self-organizing map. J. Korea Spatial Soc., 20, 13-21.

Kim, J.-Y., and D.-Y. Kim, 2013: Spatio-temporal characteristics of wind observations over South Korea: 1982-2011. AsiaPac. J. Atmos. Sci., 49, 551-560.

Lee, H. W., W. S. Jung, H. H. Leem, K. O. Lee, H. J. Choi, H. E. Ji, H. J. Lee, K. H. Sung, and W. G. Do, 2006: Analysis of local wind in Busan metropolitan area according to wind sector division - Part I: Coarse division of wind sector using meteorological observation data -. J. Environ. Sci., 15, 835-846.

Lee, J. K., 2007: A study on vehicle accidents due to strong wind. M.S. thesis, Catholic Kwandong University, Ganganeung, Korea, 55 pp.

Lee, S. Y., 2010: Forest fire occurrence status and consideration from 1960 to 2009. J. KOSHAM, 10, 51-55.

Lee, Y. G., S. S. Lee, H. J. Ham, D. H. Lee, and A. Suh, 2009: Regional wind hazard assessment to private properties. Proc. WEIIK Symposium, 58-63.

Lin, G. F., and L. H. Chen, 2006: Identification of homogeneous regions for regional frequency analysis using the selforganizing map. J. Hydrol., 324, 1-9.

Liu, Y., and R. H. Weisberg, 2005: Patterns of ocean current variability on the West Florida Shelf using the self-organizing map. J. Geophys. Res., 110, C06003, doi:10.1029/2004JC 002786.

Liu, Y., and R. H. Weisberg, 2011: A review of self-organizing map applications in meteorology and oceanography. SelfOrganizing Maps - Applications and Novel Algorithm Design, J. I. Mwasiagi, Ed., InTech, Rijeka, Croatia, ISBN 978-953-307-546-4, 253-272.
Liu, Y., R. H. Weisberg, S. Vignudelli, and G. T. Mitchum, 2016: Patterns of the loop current system and regions of sea surface height variability in the eastern Gulf of Mexico revealed by the self-organizing maps. J. Geophys. Res. Ocean., 121, 2347-2366.

Liu, Y. G., R. H. Weisberg, and C. N. K. Moors, 2006: Performance evaluation of the self-organizing map for feature extraction. J. Geophys. Res., 111, C05018, doi:10.1029/2005 JC003117.

Lu, H. C., C. L. Chang, and J. C. Hsieh, 2006: Classification of PM10 distributions in Taiwan. Atmos. Environ., 40, 14521463.

Ministry of the Interior and Safety, 2019: 2018 Disaster Year Book, MOIS, 392 pp.

Moon, Y. S., and H. J. Kim, 2001: Classification of annual and seasonal precipitation areas in Korea. J. Korean Meteor. Soc., 11, 259-262.

Nishiyama, K., S. Endo, K. Jinno, CB. Uvo, J. Olsson, and R. Berndtsson, 2007: Identification of typical synoptic patterns causing heavy rainfall in the rainy season in Japan by a Self-Organizing Map. Atmos. Res., 83, 185-200.

Park, J. K., W. S. Jung, M. K. Lee, H. M. Kim, and J. S. Lee, 2010: Pilot study in the statistical characteristics of a railroad weather-related accidents and incidents in Korea. J. Environ. Sci., 19, 917-929.

Park, K. H., K. H. Kim, D. K. Jo, and H. S. Jeon, 1994: A study on the characteristics of wind energy distribution in Korea. Energy Engg. J., 3, 187-192.

Peterson, E. W., and J. P. Hennessey, 1978: On the use of power laws for estimates of wind power potential. J. Appl. Meteor., 17, 390-394.

Pryor, S. C., J. T. Schoof, and R. J. Barthelmie, 2005: Empirical downscaling of wind speed probability distributions. $J$. Geophys. Res., 110, D19109, doi:10.1029/2005JD005899.

Um, M. J., C. S. Jeong, W. S. Nam, Y. H. Jung, and J. H. Heo, 2011: The Analysis of Optimal Cluster Number of Precipitation Region with Dunn Index. Proc. Korea Water Resources Association, 87-90.

Wan, H., X. L. Wang, and V. R. Swil, 2010: Homogenization and trend analysis of Canadian near-surface wind speeds. $J$. Climate, 23, 1209-1225.

Weisser, D., and T. J. Foxon, 2003: Implications of seasonal and diurnal variations of wind velocity for power output estimation of a turbine: A case study of Grenada. Int. J. Energy Res., 27, 1165-1179.

Wu, J. A., J. L. Zha, D. M. Zhoa, and Q. D. Yang, 2018: Changes in terrestrial near-surface wind speed and their possible cause: An overview. Climate Dyn., 51, 2039-2078.

Vesanto, J., and E. Alhoniemi, 2000: Clustering of the self-organizing map. IEEE Trans. Neural Netw., 11, 586-600.

Manuscript received 14 May 2020, accepted 17 June 2020

SOLA: https://www.jstage.jst.go.jp/browse/sola/ 